\title{
Analyzing the relationship between leadership and management based on the concept of organization management
}

\author{
Yaokui Li \\ School of Management, Taishan University,Taian271000,China. \\ liyk69@163.com
}

Key words: Leadership function, management function, organization management.

\begin{abstract}
The relationship between leadership and management is a basic problem in the theory and practice of organization management. The main reason of the disputes about the relationship between leadership and management is that their mother concept of organization management was ignored when some scholars analyzed the relationship. Leadership and management are the two basic functions of organization management. The nature of the relationship between the two is the relationship between the leadership function and the management function. The mission of leadership function is to make sure to do the correct things, while the mission of management function is to make sure to do things correctly. This is a deeper thought about Warren Bennis' opinion. The leadership function and the management function of every organization level constitute the systems of leadership function and management function of the whole organization management. The effect that the two systems have on the organization management is dynamic and complementary. Leadership and management are the two sides of one thing that are dynamic and complementary. This research result is conducive to the integration of organization management theory, and it is more conducive to make the leadership function and management function complementary in the organization management practice.
\end{abstract}

\section{1 . Introduction}

There is an abnormal and common phenomenon in organization management: when bad performance appears, most of the organization's managers understand the key reasons, and they also know how to take effective measures to solve the problem, or even a simple integration of existing resources will do, but they are always waiting for the top leader to come forward.They let the poor performance exist and spread coldly. This phenomenon is often described as performance paradox ${ }^{[1]}$. It reflects that leadership and management are divided too much in the practice of organization management. In fact, this division misunderstands and distorts the relationship between leadership and management. This division is not conducive to the realization and enhance of the organization performance in practice, and it's not conducive to the integration of organization management theory. Therefore, it is necessary to comb the relationship between leadership and management deeply by combining the theory and analyzing the organization management practice.

\section{A Review of the Main Views on the Relationship Between Leadership and Management}

There are mainly four kinds of representative views about the relationship between leadership and management ${ }^{[2]}$. The first view thinks there is no difference between leadership and management. Leadership is management and management is leadership, so leader is also manager. The second view is that management is a larger category and leadership is a function of management. The third view is that leadership is a larger category and management is one of its responsibilities. The fourth view is that leadership and management are two relatively independent areas.

In fact, the first view ignores the difference between organization management and its two micro functions: leadership function and management function. As a result, the two basic functions are both considered to be equivalent to their mother concept of organization management. 
The second view thinks management is a larger category. It really means management is the organization management of the macro level, and leadership is one of its functions. This view doesn't distinguish the concept of organization management in the macro level from the concept of management function in the micro level.

The third view pays more attention to the prominent function of leadership in practice.Because most activities are organized by the leaders, and managers are just to execute the decisions, so management belongs to the leadership. Clearly, this view is also out of the framework of organization management. In addition, this view also considers the relationship between leadership and management to be the relationship between leaders and managers.

In essence,the fourth view highlights the relative independence of leadership function and management function for the discipline construction. However, discipline construction and theoretical research can't be separated from the practice of organization management.In fact, these two kinds of relatively independent functions both serve organization management. As Daniel A .Wren says: "some modern authority makes a distinction between leadership and management, that is to say, leaders and managers are given the opposite functions, but soon we will see that this distinction will be under dispute for ever ${ }^{[3] "}$ ".

In summary, the main reason of the disputes about the relationship between leadership and management is that the mother concept of organization management was ignored when some scholars analyzed the relationship. As a result, leadership and management are both out of their mother concept and magnify their own ranges infinitely, resulting in blurring and fragmentation in understanding the relationship. The key of analyzing the relationship between them lies in distinguishing the organization management in macro level and the management as management function in micro level. Only separating the two types of management can we clarify the relationship between them from the viewpoints of theory and practice.

\section{3 . The Notable Problems about the Relationship between Leadership and Management}

Understanding the concepts of management and leadership correctly.Many famous management scholars have different definitions to the concept of management, and there are about more than 350 kinds of definitions about the concept of leadership ${ }^{[4]}$. The definitions of the basic concept are inconsistent,and different definition has different connotation. This leads to the different opinions about the relationship between leadership and management.

The relationship between leadership and management can't be equivalent to the relationship between leaders and managers.Warren Bennis, a famous American leadeship scholar, thinks that a manager is the person who does something correctly and a leader is the person who does something correct ${ }^{[5]}$. Gary A.Yukl has done a very precise evaluation about Bennis' viewpoint. He believes this view contains the hypothesis that leadership behavior and management behavior can't occur in the same person. In fact, leadership and management are two different functions, while leaders and managers are the carriers of the two functions. Leaders mainly perform the leadership function of a certain level in the organization, but the management function of this level can not be ignored, otherwise leadership function will be ineffective. On the other hand, managers can mainly perform the management function of a certain level in the organization, but the leadership function of this level can not be ignored, otherwise it will lead to inefficient or ineffective management functions.

Understanding the nature of the relationship between leadership and management correctly. The leadership function is mainly concerned with the right direction and the value of organization activities, while the management function is mainly concerned with the stability of the order and the efficiency of organization activities. The two functions in different organization levels together constitute management system and management system of the whole organization management, and the two systems constitute the organization management system. Therefore, the nature of the relationship between them is the relationship between leadership function and management function. Whether the relationship between leaders and managers or the relationship between leadership discipline and management discipline is derived from the relationship between 
leadership function and management function. So, if Warren Bennis changes the description about the manager and the leader into the description about the management function and leadership function, we can avoid the embarrassment of the conflict between management behavior or leadership behavior and their carriers. The description should be: the mission of the leadership function is to ensure doing something correct, and the mission of the management function is to ensure doing something correctly.

The relationship between leadership and management can't be considered to be the relationship between their disciplines.The relationship between leadership discipline and management discipline is based on the need of discipline construction, and they both emphasize their own emphasis. However, this emphasizing should not conceal or deny the unity of the organization management. The unity is the theory system of the organization management which is based on the organization management. That is to say, the discipline itself is independent, but the independence is relatively independent in the theoretical system of the organization management. The two disciplines have strong complementarity both in theory and in practice.

The need of theoretical research can't conceal the need of organization management practice.Some scholars think that leadership is one function of management according to the viewpoint of "management including plan, organization, leadership and control"; other scholars think that management belongs to the leadership, because leaders' function is more prominent in the organization management. We can discuss these viewpoints in two aspects. First, some theories have their own specific scopes, but we shouldn't infer their derivatives infinitely on the basis of the theory category. Secondly, although the functions of leadership and leaders are prominent, they can not break away from the categories of organization management and organization managers. In a word, the relationship between leadership and management should be analyzed according to the natural state of the organization management practice. We shouldn't distort their relationship artificially.

\section{Leadership and Management are the two Dynamic and Complementary Sides of one Thing}

Leadership and management coexist basing on the mission of organization management.If we analyze the relationship between leadership and management under their mother concept of organization management, the result will more accord with the organization management practice. Leadership and management together fulfill the mission of the organization management within the framework of organization management, and this reflects the oneness of organization management.

Leadership and management are the two complementary sides of one thing.In the practice of organization management, leadership function can’t be separated from management function, otherwise it will lead to loss of control. The reason of many disorders of micro level management such as disobeying orders and defying prohibitions,the inertia operation of the whole organization, mainly lies in excessive leadership function and inadequate management function. On the other hand, management function can not be divorced from the leadership function, otherwise it will lead to the disorientation or the collapse of the whole organization. In order to ensure the correctness of the direction and the orderliness of the organization management, the leadership function and the management function should be coordinated. Leadership function should focus on the art of organization management, management function should focus on the scientific side of the organization management, and the interaction between the two will be helpful to achieve the unity of the art and scientificalness of the organization management. The complementarity reflects their unity.

The complementary relationship between leadership and management is dynamic.The research about the relationship between leadership and management can have some practical meaning only under the dynamic organization environment. It's meaningless to emphasize the strength or weakness of either party under the static organization environment. First, this dynamic nature is embodied in the primary and secondary relationship configuration between the leadership function and the management function. The relationship configuration should be based on the mission of the organization management, that is to say, the division of labor of the two functions 
always changes dynamically with the organization environment. Secondly, the dynamic nature is embodied in the practice carriers of the two functions. The points which are concerned by the leaders and the managers always change dynamically between the two functions. The traditional leaders especially some senior leaders often break away from the grassroots, and this means the leadership function breaks away from the grassroots. Once leadership function breaks away from the grassroots, it is difficult to imagine what the organization performance will be. Whether the leaders or the managers are both the organization managers, and they should work around the organization management, but the emphasis they focus on often changes with the emphasis of organization management in different period of organization development. In a specific period, whether the leaders or the managers should strengthen the leadership function or the management function of the whole organization management, because they are organization managers, and they shouldn't be confined to the division of the functions. It is wrong that one function exits while the other appears. Otherwise, the leadership function will be weakened because of the lack of management function, and the organization management will be out of order because of the lack of leadership function. Leaders can find the right direction of their activities by strengthening management function. Managers can ensure the right direction of their activities by strengthening leadership function, and this is helpful to make their activities consistent with the whole organization's leadership function system highly.

\section{5 . Conclusion}

From the logical viewpoint, whether the concept of leadership or the concept of management will extend their own scope infinitely once they break away from the concept of organization management. Two things should be compared to in a specific range, otherwise the comparation will be meaningless. From the practical viewpoint, once leadership or management breaks away from the organization managemen and its mission, the whole organization management will get into the trouble of too microscopic state, and the whole organization management system will operate in a low level. This will eventually lead to the inefficient integration of the organization resources and poor organization performance. We have discussed the relationship between leadership and management under the mother concept of organization management.We think the nature of the relationship between leadership and management is the relationship between leadership function and management function, and we think they are two sides of one thing that are dynamic and complementary. As a result, leadership function and management function are the two basic functions of the organization management, leaders and managers based on the traditional concept are both organization's managers, while leadership discipline and management discipline both belong to the organization management discipline. This research can help to solve the problem that leadership and management including their related concepts may be separated in theory and in practice, it is conducive to the integration of organization management theory, and it is more conducive to make the leadership function and management function complementary in the organization management practice. It's their original relationship.

\section{References}

[1]Yu-Ping Xi,performance paradoxhttp://www.chinahrd.net/hr_gl/zhengda_wh/Content.asp?id=1321

[2]Li-Yan Zhu, Administrative leadership, $3^{\text {rd }}$ edn. (Publishing House of Renmin University of China,Beijing, 2015), 20-21.

[3]Daniel A .Wren, The Evolution of Management Thought (Translators:Zhu-Liu Li, Rui Zhao)( Publishing House of Social Science of China, Beijing, 1997),494.

[4]Li-Yan Zhu, Administrative leadership, $3^{\text {rd }}$ edn. (Publishing House of Renmin University of China,Beijing, 2015), 26. 
[5]Gary A.Yukl, Leadership in Organizations , $5^{\text {th }}$ edn. (Translators: Wenzhao Tao) , (Publishing House of Renmin University of China,Beijing, 2004), 6. 